\title{
Knowledge creation and knowledge diffusion in space and regional innovation performance: introductory remarks
}

\author{
Roberta Capello • Attila Varga
}

Published online: 9 June 2013

(C) Springer-Verlag Berlin Heidelberg 2013

This special issue of the Annals of Regional Science provides an up to date state of the art in understanding the complex relationship between knowledge creation, knowledge diffusion, regional innovation, and local economic performance. Research on this issue dates back to the eighties when the neoclassical approach of innovation as a manna from heaven was left aside, and contributions in the field of innovationdriven regional development were put forward. Concepts like innovative milieux, technological districts, regional innovation systems, learning regions, etc., have been introduced at that time to underline the importance of space and regions, as key drivers of innovation (Camagni 1991; Cooke 1992; Storper 1992; Asheim 1996).

Nowadays, the issue of knowledge creation and diffusion in determining growth performance is still a hot topic for different reasons. On the one hand, the normative strategy around the European Union's Agenda 2020 calls for ad hoc innovation policies to move toward a knowledge-intensive growth model for Europe on a regional base, supplying operational answers to the request of one of its 'flagship initiatives', namely 'Innovation Union' (EC 2010). On the other hand, the role of space in knowledge creation and diffusion processes requires additional thoughts largely expanding from the initial simple interpretation of space as a geographic barrier. In fact, over time, a strong belief accompanied innovation studies at local level that not only spatial proximity matters as a channel for knowledge transmission, but different types of cultural, social, and cognitive proximities make the difference: "being simply there" is not enough (Boschma 2005; Capello 2009; Breschi and Lissoni 2001; Capello

\footnotetext{
R. Capello ( $\square)$

Politecnico di Milano, Milan, Italy

e-mail: roberta.capello@polimi.it
}

\author{
A. Varga \\ University of Pécs, Pécs, Hungary \\ e-mail: vargaa@ktk.pte.hu
}


and Caragliu 2012). It has been argued that two very closely located actors may have little knowledge to exchange and that innovative production usually requires the combination of dissimilar, although related, complementary knowledge (Boschma and Frenken 2010; Boschma and Iammarino 2009).

Moreover, spatial proximity complements other forms of knowledge acquisition; in particular, formal, intentional relations based on coordinated and well-defined linkages between actors who might, or might not, be in close spatial proximity, has been identified as a channel of knowledge acquisition (Camagni 1991; Bathelt et al. 2004; Maggioni et al. 2007; Maggioni and Uberti 2009; Varga et al. 2013). The need for firms to network with extra-local knowledge pools has been interpreted as a way to overcome potential situations of regional 'entropic death', 'lock-in', or 'over-embeddedness' (Boschma 2005; Camagni 1991; Grabher 1993; Uzzi 1997). These claims have contributed to a lively current debate among research streams about the conditions in which tacit knowledge can be transmitted at a distance and go beyond a region's confines, as well as the extent of such transmission (Miguelez and Moreno 2013).

Spatial and a-spatial proximities are the crucial elements to understand knowledge creation and diffusion, and therefore innovation performance. Much has been said, but our current understanding of knowledge flows, and its relationships with regional innovation patterns, space, and economic growth still needs both further theoretical as well as empirical analysis. With respect to the existing literature, this special issue provides new conceptual insights into the diffusion processes of knowledge and innovation accompanied by new rigorous empirical analysis on the importance of knowledge networks as channels for knowledge exchange at both local and inter-regional levels.

The richness of the papers in this special issue is their capacity to enter in welldocumented issues and demonstrate that they still call for additional thoughts and empirical validation. It is the case of the role of urbanization economies that since Jacobs (1969) include knowledge spillovers at the regional level requiring the presence of bright, creative, and innovative prone entrepreneurship to make use of urban density as a channel for knowledge exchange (Bosma and Van Oort, in this special issue). It is the case of the analysis of local inter-firm labor mobility as a channel for local knowledge spillovers (Andersson and Thulin, in this special issue). It is the case of local knowledge spillovers that, in order to generate increases in innovation output, require a high local mobility of inventors (Miguelez and Moreno, in this special issue). It is the case of the need to differentiate both conceptually and empirically between knowledge (invention) and innovation (commercialization of a new idea) in order to interpret the different "regional patterns of innovation" (Capello and Lenzi, in this special issue).

The papers in this special issue all deal with the mechanisms of knowledge creation and diffusion on regional innovative performance and economic growth. They all depart from the simple idea that geographic proximity is a channel of knowledge transmission, thanks to higher density face-to-face contacts. This epidemiological approach to knowledge exchange is substituted by a careful search for local channels of knowledge transmission, from local labor mobility of inventors to inter-firm labor mobility, to the presence of innovation-prone entrepreneurs. Moreover, they all depart from the simple idea that knowledge diffusion takes place only locally and instead 
enter in depth in the mechanisms of knowledge acquisition through inter-regional cooperation, going a step forward from what is present in the literature, and adding (both in conceptual and empirical terms) quality aspects of cooperation in the analysis of inter-regional knowledge flows (Sebestyén and Varga, in this special issue).

The ordering of the papers is not casual; it approaches knowledge diffusion with an inter-regional perspective, followed by a local, intra-regional perspective. As such, the aim of the special issue is to drive the reader through all conceptual novelties contained in the understanding of the complex spatial processes of knowledge creation and diffusion, separating out the inter-regional and the intra-regional mechanisms. The contributions at the inter-regional level aim to go in depth into the mechanisms behind cooperation attitudes, while the ones at the local level present the goal of overcoming the epidemiological approach of spatial proximity as the main source of local knowledge spillovers by identifying the local channels through which knowledge spreads around.

The first paper by Roberta Capello and Camilla Lenzi highlights the importance of separating out the invention phase from the commercialization phase, if one wants to interpret modes of innovation at the regional level. Knowledge and innovation are not necessarily overlapping processes in space nor necessarily sequential at the local level, and different types of knowledge (e.g., formal vs. informal) may be needed to innovate in different contexts. Accordingly, alternative situations can be conceived; for example, there can be regions where innovation builds on internal knowledge, or where local creativity compensates for the lack of local knowledge and allows for an original application of external knowledge acquired via scientific linkages, or where innovation is achieved through an imitative process of innovation external to the region. The paper presents a territorial taxonomy of innovative regions based on a new conceptual approach, which interprets not only one single phase of the innovation process, but the different modes of performing the different phases of the innovation process, highlighting the context conditions that accompany each 'territorial pattern of innovation'. The paper conceptually derives different territorial patterns of innovation and identifies them empirically for European regions. The interest in the new taxonomy lies on the fact that the recent policy approach to innovation calls for thematically/regionally focused innovation policies in line with the place-based approach (EC 2010). To achieve this goal, without incurring the unrealistic situation of having one policy action for each European region, a sound taxonomy on innovative European regions is required. The existing taxonomies are somewhat unsatisfactory, since they group European regions only on the basis of the intensity of their knowledge production, taking it for granted that knowledge equates innovation, leaving no space to inter-regional knowledge spillovers for knowledge creation and innovation diffusion.

The second paper by Tamás Sebestyén and Attila Varga draws attention to the importance of the quality of a particular inter-regional network for a particular region. This quality is reflected by the contribution of knowledge accessed in the network to the production of new knowledge inside the region. In order to make the problem empirically tractable, the authors quantify certain features of inter-regional networks that could be instrumental for regional knowledge production additional to what have already been accounted for in the spatial literature (i.e., number of partners and their knowledge levels) and present a novel comprehensive index to account for the quality of a 
region's global knowledge network, what they call an index of 'ego network quality' (ENQ). The higher this index value gets, the larger the amount of knowledge potentially accessed from the network will be. To test the validity of the new network measure, a systematic spatial econometric analysis is carried out with European data of 189 NUTS 2 regions. Specifically, the role of the quality of collaboration networks in research addressing the development of technological inventions (measured by patents) on the one hand and scientific publications on the other is analyzed. They find that the quality of inter-regional networks in both areas of knowledge production is indeed a significant contributor to $\mathrm{R} \& \mathrm{D}$ productivity. It is also found that the pure number of collaborations, which is the most frequently used variable in spatial network studies, is not a suitable proxy of inter-regional network effects in R\&D productivity contrary to ENQ. Their results show that a more comprehensive approach taking into account several local and global features of the network surrounding the given region provides better insights into the network effects in regional knowledge production.

The third paper by Ernest Miguélez and Rosina Moreno deals with an analysis of the contribution made by research networks and the local and geographic mobility of inventors to the process of knowledge creation. By means of a knowledge production function and a sample of 276 European regions, the authors assess whether local labor mobility of inventors, as well as the scale and extent of their collaborative research networks, correlates with innovation outcomes. In the second part of the paper, they extend the analysis to the role of spatial mobility of knowledge workers and crossregional research networks as predictors of regional patenting. Results witness that both mobility and networks (within and between regions) explain a sizeable part of the spatial heterogeneity of innovation rates.

The fourth paper by Niels Bosma and Frank van Oort opens the black box of urbanization economies as drivers of more intensive knowledge exchange and therefore of productivity increases, by trying to identify the channels through which knowledge diffuses at the local level. The authors introduce specific types of entrepreneurship, discerned at the individual level, as well as human capital and invention through patenting activity. The empirical application on 111 regions across 14 European countries investigates their relation with regional productivity rates. The main findings indicate that (i) human capital, patenting activity, and entrepreneurship are all linked to regional performance, more so in regions containing large as well as medium-sized cities; (ii) they act as complements rather than substitutes, facilitating productivity differently; and (iii) accounting for patenting activity and entrepreneurship captures agglomeration externalities effects previously subscribed only to the density of resources of regional performance. The particular role of regions with medium-sized cities next to regions with large cities complies with observed growth trends as well as recently proposed place-based development approaches that assume that interactions between institutions and geography are critical for regional economic performance.

The fifth paper by Martin Andersson and Per Thulin focuses on a much cited but seldom measured micro-foundation for agglomerations: inter-firm labor mobility. Labor mobility has been advanced as a vehicle for knowledge flows and labor market efficiency, and is often maintained to be an important source of agglomeration economies. Based on an extensive matched employer-employee dataset, they estimate the influence that spatial employment density has on the probability of inter-firm 
job switching, while controlling for ample attributes of each worker and employer. The analysis shows that the rate of inter-firm labor mobility varies substantially across regions, and they document a systematic and robust positive influence of density on the probability of job switching. The likelihood that such switching is intra-regional is significantly higher if the employees operate in denser regions, verifying that labor mobility (and thus, the effects mediated by it) is indeed localized. Higher rates of inter-firm labor mobility appear as a likely mechanism behind the empirically verified productivity advantage of dense regions.

The sixth paper by Wan-Hsin Liu investigates whether proximity to universities matters for corporate patenting in Chinese provinces as evidenced for Western economies in the literature. The investigation is based on estimating regional knowledge production functions using a Chinese provincial dataset for the years from 2000 to 2008. Geographic proximity of companies to universities is taken as a key element to measure firms' accessibility to university research. In addition, quality-adjusted accessibility measures are considered in extended models to take into account quality difference in university research. The results suggest the existence of spatial spillover effects of universities on corporate patenting activities in China. These effects are especially strong for realizing technologically less demanding non-invention corporate patents than for invention corporate patents. Moreover, quality difference in university research is found to be less important for determining academic spillover effects on corporate patenting than firms' geographic proximity to universities. Extended models are estimated for robustness checks, which ascertain the main results.

Taken together, these six papers succinctly capture the advances in spatial knowledge creation and diffusion channels. Reading the papers, it becomes evident that although it is clear that research in this field has made enormous advances over the last decade, it is also clear that still much remains to be conceptualized and analyzed through sophisticated empirical analyses and that this special issue is a step in this direction.

\section{References}

Asheim BT (1996) Industrial districts as 'learning regions': a condition for prosperity. Eur Plan Stud 4(4):379-400

Bathelt H, Malberg A, Maskell P (2004) Clusters and knowledge: local buzz, global pipelines and the process of knowledge creation. Prog Hum Geogr 28:31-56

Boschma RA (2005) Proximity and innovation: a critical assessment. Reg Stud 39(1):61-74

Boschma RA, Iammarino S (2009) Related variety, trade linkages, and regional growth in Italy. Econ Geogr 85(3):289-311

Boschma R, Frenken K (2010) The spatial evolution of innovation networks. A proximity perspective. In: Boschma R, Martin R (eds) The handbook of evolutionary economic geography. Edward Elgar, Cheltenham, pp 120-135

Breschi S, Lissoni F (2001) Localised knowledge spillovers vs. innovative milieux: knowledge "tacitness" reconsidered. Pap Reg Sci 80(3):255-273

Camagni R (ed) (1991) Innovation networks. Spatial perspectives. Bellhaven Press, London

Capello R (2009) Spatial spillovers and regional growth: a cognitive approach. Eur Plan Stud 17(5):639-658

Capello R, Caragliu A (2012) Proximities and the intensity of scientific relations: synergies and nonlinearities, paper presented at the Tinbergen Institute, held in Amsterdam, May, 7-8

Cooke P (1992) Regional innovation systems: competitive regulation in the new Europe. Geoforum 23: $365-382$ 
European Commission (EC) (2010) Regional policy contributing to smart growth in Europe. COM(2010) 553, Brussels

Grabher G (1993) The weakness of strong ties: the lock-in of regional development in the Ruhr area. In: Grabher G (ed) The embedded firm. Routledge, London, pp 255-277

Jacobs J (1969) The economy of cities. Random House, New York

Maggioni M, Nosvelli M, Uberti E (2007) Space versus networks in the geography of innovation: a European analysis. Pap Reg Sci 86(3):471-493

Maggioni M, Uberti E (2009) Knowledge networks across Europe: which distance matters? Ann Reg Sci 43(3):691-720

Miguelez E, Moreno R (2013) Do labour mobility and networks foster geographical knowledge diffusion? The case of European regions. Growth Chang 44(2):321-354

Storper M (1992) The limits to globalization. Technology districts and international trade. Econ Geogr 68(1):60-93

Uzzi B (1997) Social structure and competition in interfirm networks: the paradox of embeddedness. Adm Sci Q 42:35-67

Varga A, Pontikakis D, Chorafakis G (2013) Metropolitan Edison and cosmopolitan Pasteur? Agglomeration and interregional research network effects on European R\&D productivity, forthcoming in the Journal of Economic Geography 